\title{
The Impact and Inspiration of The College English Education Model By
}

\section{MOOCs}

\author{
LI Zhaoying \\ Jilin Business and Technology College, Changchun 130000,China \\ lizhaoying@126.com
}

Keywords: MOOC; Education; College English; Education mode

Abstract. With the appearance and development of MOOC, the education of college English has been impacted greatly, and the influence is mainly shown in the following aspects: traditional education mode; the class structure; the relation between students and teachers and the ability and quality of the teacher and so on. MOOC is a great challenge to college English education, however, on the other hand, it also brings college English education reform and opportunities. The college English education must combine general English with esp. teaching; The MOOCs can be selectively moved to our offline classrooms, where the traditional classroom is "MOOC". It is also suggested to advocate teachers with an international vision and high quality.

\section{The Impact of MOOC On the Education On the College English Education}

In recent years, with the rapid development of modern information technology, "MOOCs massive open online courses" has come into being, which means large-scale online open courses. Since 2012 when the year was named the Year of MOOC, the research and longing for MOOC has quickly spread the world. In the year 2013, China joined the international MOOCs camp and became a member of the world MOOCs, beginning to build our own MOOC classes and web resources. A large number of researchers and scholars are also involved in the construction, reform and research of the course. The MOOC is a kind of information technology which has developed in recent years with the rapid development of modern information technology. They are widely integrated into every field of society and the word "MOOCs-massive open online courses" has the meaning of mass online courses. At present the world's courses from the three largest MOOC platform more than eighty percent is presented in whole English teaching. The year 2012 was named the International MOOC Year. Ever since then, the influence of MOOC is becoming stronger and stronger. In the same year, China entered the MOOC Year and a lot of colleges have come into the MOOC camp. 212

The coming of the MOOC era has brought new ideas and development paradigm to the traditional pattern of English teaching in China and brings huge impact to college English teaching. With the expansion and development of international domestic MOOCs, Chinese students are finally able to look at foreign language education. The traditional way of learning English concluding learning words by heart, memorizing some good articles, listening to English broadcast in the past has now been questioned. When college students enter the MOOC class platform, they come to understand what English listening really is .On the platform the students find the language of the teacher is quite different from what they heard before .Compared to the past, students were in the simpler environment of language, so it is not so hard for them to get what their teacher said as on the MOOC platform. In the course of MOOC, students find it difficult to understand the teacher's 
classroom language and communicate with other learners in the world. The popularity of MOOC has taught English learners and educators to think: what's the matter with our college English education? MOOC has posed a huge challenge to the traditional university foreign language education.

\section{The Challenge to Traditional Teaching Resources}

Traditionally in the college English teaching, generally speaking one teacher is in charge of one to three classes' English course. Students get limited English knowledge and relative language skills from this teacher. So the result is they get relatively limited knowledge or language resources. The quantity of classes in a week is limited to 4 to 6 . As a result, students' language learning is greatly restricted. At the same time, based on the limited teaching resources, the teaching method of the teacher is also more singular and stylized. Generally speaking, the existing college English teaching is mainly the combination of teaching material, blackboard and PowerPoint presentation.PPT is the counterpart of the teaching material, or is the concentration of the teaching material, teachers in class are nothing more than a word a text structure, language points on practice a few general steps, such as language teaching becomes a stylized model.

\section{A Challenge To traditional Class Instruction and Relation Between Teacher and Students}

The coming of the MOOC era has brought new ideas and development paradigm to the traditional pattern of English teaching in China and brings huge impact to college English teaching. With the expansion and development of international domestic MOOCs, Chinese students are finally able to look at foreign language education. The traditional way of learning English concluding learning words by heart, memorizing some good articles, listening to English broadcast in the past has now been questioned. When college students enter the MOOC class platform, they come to understand what English listening really is .On the platform the students find the language of the teacher is quite different from what they heard before .Compared to the past, students were in the simpler environment of language, so it is not so hard for them to get what their teacher said as on the MOOC platform. In the course of the MOOC, students find it difficult to understand the teacher's language and communicate with other learners in the world. The popularity of MOOC has taught English learners and educators to think: what's the matter with our college English education? MOOC has posed a huge challenge to the traditional university foreign language education.

In the traditional college English classroom structure, the class is mainly operated by the teacher who comes when it is time for class and gives the lecture and answers the questions from the students and after class leaves. As a result, the interaction between the teachers and the students exchange rarely, which leads to the result that the students cannot understand the teacher and the teacher feels it not easy to know how much the students have got from his lessons. Therefore it is nearly impossible for the teacher to reach the goal of teaching students in accordance of their aptitude. It seems that the teacher is trying to fulfil a task and when the task is over, the teacher can leave.

However, the MOOC overturns the traditional classroom which treats the teacher as the centre and the one---way pattern of knowledge ; The MOOC changes the structure that students study passively and it is calling for a more scientific and reasonable system of interaction between teachers and students, which is a win-win ecological classroom model, a typical so student-centered teaching design course. In such a class mode, an English learning environment is created, classic English learning resources are provided and there is an online interaction and living 
online real-time interaction between teachers and students, to improve the teaching quality, to create high-quality foreign language courses.

\section{Challenge the Teaching Ability and Quality of English Teachers}

From the analysis above we can see that MOOC is a great challenge to traditional teaching resources and traditional relations between teachers and students, and MOOC puts forward a higher requirement for college English teachers' teaching ability and high-quality. In a traditional class, the teacher gives a lesson with the help of a book, a note and sometimes a courseware and when class is over, there is little time for students to discuss and raise questions.

However in a MOOC class, usually before class, a micro video is provided which takes about 10 to twenty minutes for students to watch and think about. In class the main task is a "improvisation" by teachers. This improvisation is completed not so easily because in the course of the MOOC, the teacher will not only face the college students who are 20 years old or so and has less knowledge and experience than the teacher himself, but also the teacher will meet some older learners who want to get more than the students. Usually the MOOC is made up of three parts: the micro video phase; discussion stage and evaluation stage. First the teacher spends about 10 minutes in presenting the micro video which requires the teacher's clear infectious generalization ability, expression ability and language art; In the discussion stage, the teacher is required to understand his students quickly and quickly grasp the students' questions and using agile thinking, concise, popular and simple language for students to answer questions; In the evaluation stage, In the evaluation stage, the teacher should have more language skills and be good at must be good at evaluating student performance using different wording. In a word, teacher's academic background, knowledge, epistemology, value orientation, teaching charm all levels will constitute curriculum is an important factor of attractive to students.

\section{The Inspiration of the MOOC View To the Education of the Chinese University}

MOOC is threatening traditional college English class with many advantages, however, based on the character of Chinese students, it is nearly impossible for MOOC to completely take the place of traditional college class. Then what inspiration can we get from MOOC and how should offline stand firm in the tide of the development of their own place?

The Organic Combination Between General English And ESP

At present among the courses provided by the 3 international MOOC platform, eighty percent are taught in

complete English, which is a problem to us Chinese learners. Those who are interested in specialized knowledge have much difficulty in understanding what the teacher says and those who have no problem in understanding have no idea of the specialized knowledge. Therefore such situation creates development trend. General English must be combined with specialized English. It is suggested that a pure language foundation course is set up at the beginning of the college. Specialized knowledge can be taught after that. So in the aspect of teachers, it is suggested that general English be combined with specialized English.

\section{Cultivate High-quality English Teachers With International Vision}

The Chinese college students have seen the elegance and charm of famous colleges and universities and well-known teachers from the MOOC platform. A lot of students are feeling a bit emotional when they come on the MOOC platform. If only our teacher could do like that, my English level 
would be better. That gives us a lesson which is a fact we have to accept. The entire quality of our college English teachers is not so satisfactory. Many of the teachers go straight to the lectern from school, for decades, they work every week .Only a few of them have the chance to go abroad or go to other places for further study. Their vision is comparatively small and they know not much about language and culture of English speaking countries. What they give to their students from English textbooks and sometimes on the web is limited only because they are lack of personal awareness and the feeling of English speaking countries. That is the reason why what they taught is lack of vitality and cannot arouse students' interest.

On the other hand, teachers' teaching skills are not so satisfactory and needs to be improved .In our traditional English class, a general pattern is followed by most of the teachers: import---a background of knowledge---words---a text---some practice about the text. All these need a kind of innovation and the students who are familiar with the teachers' general paradigm feel uninterested in what the teachers give it. That is to say they have lost their passion for studies.

Good university education should be like this. Students are often encouraged to think positively and are often provided with hard training in textbooks. College English teachers should understand this. Much of their time is spent in the knowledge on the surface such as explaining the new words in the text, grammar, and the text translation. What they should mainly do is to guide their students to autonomous learning and to encourage them to question ,evaluate and innovate.

Secondly the teaching language of English teachers is very important to the class. Some of the teachers' language (including body language ) is not satisfactory. A really charming English teacher should be a versatile teacher with some kinds of qualities such as speaker, actor, eloquent speaker, psychologist, etc.

This requires teachers' personal training. In addition to that, the college needs to make efforts to cultivate a large number of high qualitied teachers with broad vision and forms a good demonstration effect.

\section{Conclusion}

In 2007,the ministry of education issued College Curriculum requirements .In the requirements, the college English teaching mode based on the computer and the class is put forward, which gives higher requirements for college English teachers. They should try to stimulate students to a variety of sensory participate in language learning and improve students' learning efficiency by multimodal. Class presentation according to the characteristics of the English language In order to further implement the requirements the education ministry has set up a special project which is on the English teaching in colleges, which is used to guide colleges and universities to implement the college English teaching model based on the computer and the class in order to promote the comprehensive integration of information technology and university English courses.

The appearance of MOOC exactly complied with what the college English teaching requires in our country. We should take advantage of the advantages of resources provided by MOOC class and improve our traditional offline teaching and combine both two modes.

This article analyses the challenges and revelation the MOOC class brings us and provides some suggestions. Realizing there are a lot of shortcomings in our college English teaching. They ought to realize their personal shortcomings and try to make up for what they are lack of. Trying to get more new education view idea and other valuable resources, the teacher should improve their own business level and their comprehensive quality making our traditional offline education more perfect more successful. 


\section{Reference}

[1] "MOOCs" (MOOCs), College English Audio-visual and Audio-visual Instruction [J]. Journal of the University of China (2004).

[2] The Flipped Classroom Mode Based on the English Teaching and Teacher Relationship [J]. Ye ling, Xu chongyu, Zhang guoying. Chinese Medicine Education Technology. 2015 (02).

[3] The Impact of MOOCs on College English Teachers [J]. Journal of Engineering and Technical Teachers College of Engineering, China. (2006)

[4] The Advantages of "MOOC" and Challenge to the College English Teachers [J]. Sun shuxia. Journal of Lanzhou Petrochemical School of Technology. 2015 (2003).

[5] The Application and Development of MOOCs in English Teaching [J]. Journal of the Jilin Institute of Chemical Technology. (10)

[6] Learning Theory Based on the Principle of "Import" in the College English Class [J]. Journal of Zunyi Teachers College, 2015 (2005)

[7] Microlectures on the Learning of Chinese Culture in the English Classroom [J]. Knowledge Economy. 2015 (19)

The Transformation of Teacher Roles in the Course of the

[8] MOOC: Competition and Choice [J].

[9] Based on General Academic English Hearing Inversion of Classroom Research [J]. 